\title{
Consideration of immediate and future consequences, perceived change in the future self, and health behaviour
}

\author{
Tatiana Pozolotina, UiT The Arctic University of Norway \\ Svein Ottar Olsen, UiT The Arctic University of Norway
}

Corresponding author: Tatiana Pozolotina, School of Business and Economics, UiT The Arctic University of Norway, N-9037 Tromsø, Norway.

Telephone: +47 776 23292, email: tatiana.m.pozolotina@uit.no.

Co-author: Svein Ottar Olsen, School of Business and Economics, UiT The Arctic University of Norway, N-9037 Troms $\varnothing$, Norway.

Telephone: +47 77646 000, email: svein.o.olsen@uit.no.

To cite this article: Tatiana Pozolotina \& Svein Ottar Olsen (2019) Consideration of immediate and future consequences, perceived change in the future self, and health behavior, Health Marketing Quarterly, 36:1, 35-53, DOI: 10.1080/07359683.2019.1567003 


\begin{abstract}
The present study investigated the link between consideration of immediate and future consequences (CFC-I and CFC-F), and perceived change in the future self (PCFS) to healthy and unhealthy behaviours. Furthermore, we explored the moderation effect of PCFS on the relationship between CFC-I and CFC-F and health behaviours. We observed that CFC-I was linked to unhealthy behaviours, whereas CFC-F was associated with healthy behaviours. PCFS had a direct negative effect on healthy behaviours, and as a moderator, it strengthened the positive effect of CFC-I and dampened the negative effect of CFC-F on unhealthy behaviours. Implications for health communication are discussed.
\end{abstract}

Keywords: exercise, future self-continuity, healthy eating, intertemporal choice, moderation, perceived connectedness, smoking, temporal discounting 


\section{Introduction}

The pattern of health behaviour is composed of many small decisions we make on a daily basis, such as the food we chose for breakfast today, whether we decide to go for a walk or lie on the sofa in the evening, or how many drinks we chose to have at the party last weekend. However, in many instances, individuals face the consequences of following their immediate desires much further in the future. Therefore, we can say that health behaviour is an intertemporal choice, i.e., a "decision in which the timing of costs and benefits is spread over time" (Loewenstein \& Thaler, 1989, p. 181).

As a rule, people prefer to get a reward sooner than later; such a tendency is called time preference (Frederick, Loewenstein, \& O’Donoghue, 2002). As a result, the value of costs and benefits decreases over time (Loewenstein \& Prelec, 1992). Thus, the true conflict between sooner and later options can only occur when an individual chooses between a smaller sooner and a larger later option, i.e., when there is a bonus for postponing a reward. In the case of health behaviour, the small present rewards of unhealthy behaviour or costs of healthy behaviour are outweighed by a much larger health impact in the long run. The trade-off between satisfying immediate desires and attaining future benefits has been studied in the area of education (Volder \& Lens, 1982), environmental behaviour (Milfont, Wilson, \& Diniz, 2012), consumer behaviour (Verplanken \& Sato, 2011), saving behaviour (Ersner-Hershfield, Wimmer, \& Knutson, 2009), ethical behaviour (Ersner-Hershfield, Cohen, \& Thompson, 2012), and health behaviour (Zimbardo \& Boyd, 1999).

The present work aims to expand our understanding of the underlying mechanisms of health behaviour choices. The paper addresses two constructs that could potentially influence health behaviour on a personal level: consideration of future consequences (CFC) and perceived connectedness/ change in the future self (PCFS). The first objective of the present research was to 
provide a further insight into the relationship between time perspective and health behaviours. The study focused on the link of the two dimensions of $\mathrm{CFC}$, consideration of immediate consequences (CFC-I) and consideration of future consequences (CFC-F), to smoking, healthy and unhealthy eating, and physical activity. We included both healthy and unhealthy behaviours in our research in order to test whether CFC-I and CFC-F could potentially differentially predict these categories of health behaviour. Moreover, previous studies show that healthy and unhealthy behaviours are conceptualised differently (Povey, Conner, Sparks, \& James, Shepherd, 1998) and have different responses to intervention (Adriaanse, Vinkers, Ridder, Hox, \& Wit, 2011). As a second contribution to the existing theory of health behaviour, the study explored the effects of perceived connectedness/ change in the future self on health behaviours and its moderating effect on the relationships between CFC-factors and health behaviours.

\section{Consideration of future consequences}

Consideration of future consequences (CFC) is 'the extent to which individuals consider the potential distant outcomes of their current behaviours and the extent to which they are influenced by these potential outcomes' (Strathman, Gleicher, Boninger, \& Edwards, 1994, p. 743). Low CFC people tend to focus more on their immediate versus their future needs. In contrast, those high in CFC consider the future implications of their behaviour.

A series of studies presents evidence that high CFC is positively associated with personality traits related to self-control, including conscientiousness and delay of gratification, as well as long-term thinking and future-oriented behaviour. For instance, Joireman, Lasane, Bennett, Richards, and Solaimani (2001) found that higher CFC is associated with stronger pro-environmental intentions, greater involvement in pro-environmental behaviour, and a stronger belief in the personal, social 
and biospheric consequences of environmental conditions. Sirois (2014) discovered a significant correlation between low CFC and procrastination. Peters, Joireman, and Ridgway (2005) showed that higher CFC is associated with higher school grades, whereas lower CFC is related to the tendency to miss classes due to oversleeping. Ouellette, Hessling, Gibbons, Reis-Bergan, and Gerrard (2005) presented an association between high CFC and a higher level of exercise behaviour.

Later research has shown that a two-dimensional model of CFC with consideration of immediate and future consequences could contribute to a more accurate description of reality, as the present and future dimensions do not have to be mutually exclusive, as some people could potentially be equally concerned about immediate and future consequences of their actions. Furthermore, there is evidence that a two-factor CFC model demonstrates a better data fit (Adams, 2012; Joireman, Balliet, Sprott, Spangenberg, \& Schultz, 2008; McKay, Percy, \& Cole, 2013; Toepoel, 2010). CFC-I describes a general preoccupation with immediate outcomes whereas CFCF illustrates a preoccupation with future outcomes of one's actions. The existing research provides mixed results as to which factor is predictive of intertemporal choice and health behaviour. Joireman et al. (2008) found an association of high levels of CFC-I with lower self-control. Rappange, Brouwer, Job, and Van Exel (2010) demonstrated a significant correlation between two factors of the CFC model and temporal discounting. Adams (2012) showed that high CFC-I is associated with smoking status and a higher BMI index. On the other hand, McKay et al. (2013) found a significant correlation only between CFC-F and problematic drinking behaviour. Thus, the first objective of our study was to test the relationships between CFC-I, CFC-F, and different health behaviours. 
Regarding health behaviour as an intertemporal choice, we considered four scenarios that helped us formulate our hypotheses. The first scenario describes individuals who choose small benefits provided by unhealthy behaviours in present time, for instance, satisfying the urge to smoke or enjoying unhealthy food; whereas larger health costs occur in the far future in the form of diseases, such as heart problems, lung cancer, and, as a result, poor life quality, or even earlier death. The second perspective is that individuals avoid smaller health investments in the present, for instance, when they prefer not to go to a fitness class or postpone their visit to the dentist, thus sentencing themselves to larger health costs in the future. The third viewpoint is that minor costs, for instance, physical effort, time, and financial investment, are paid in the present to achieve better health in the future. To illustrate such behaviours we can mention going out for a walk and exercising, paying to visit a fitness centre, or dancing classes. The fourth scenario is that minor benefits are foregone at the present time in order to obtain larger health benefits in the future. Avoiding the pleasure of a portion of unhealthy food or alleviation of a smoking or a drinking urge, could be named as examples of sacrificed immediate benefits.

Individuals scoring high on CFC-I are concerned with the immediate consequences of their actions. Thus, we expected that individuals scoring high on CFC-I would prefer the short-term benefits provided by unhealthy behaviours, in our case, smoking and unhealthy eating (positive relationship), and avoid paying today's costs of health behaviours, i.e., healthy eating and physical activity (negative relationship).

High CFC-F individuals are concerned with the future consequences of their actions. Thus, we expected they would be more willing than low CFC-F people to engage in healthy behaviours in order to obtain good health in the future and avoid the temptation of short-term benefits provided by unhealthy behaviours. 
Thus the first four hypotheses were:

H1: CFC-I is positively related to unhealthy behaviours.

H2: CFC-I is negatively related to healthy behaviours.

H3: CFC-F is negatively related to unhealthy behaviours.

H4: CFC-F is positively related to healthy behaviours.

\section{Perceived connectedness/ change in the future self}

Another possible explanation for personal differences in temporal discounting-influencing intertemporal choice — and, thus, health behaviour, could be found in the theory of multiple selves. Parfit (1971) describes a person in time as a model of multiple selves, i.e., a person in the present time and the same person in any time in the future are different selves. However, there is psychological continuity between the present and the future selves, as more close in time selves share more features with one another. The more features the selves share, the more connected they feel to one another. If one does not anticipate sharing many psychological features with a distant future self and is unsure of the qualities the distant self will have, one feels less connected to one's future self. Therefore, this self is regarded more like a stranger, and thus one feels less psychologically attached to it and cares less about its benefits. As a result, the outcome of the conflict between the present self's and the future self's interest, i.e., intertemporal choice, will be largely decided by the degree to which one feels psychologically connected to the future self and, thus, cares about that self. In other words, if one perceives oneself in the future as a stranger, one tends to care less about that unknown person.

A number of recent studies found an association between connectedness to the future self and discount rates. Ersner-Hershfield, Wimmer, et al. (2009) provided neurological evidence that people differ in connectedness to their future self. Participants who had more connectedness to 
their future selves demonstrated lower discounting rates. In later studies Ersner-Hershfield, Garton, et al. (2009) demonstrated that individuals with higher future self-continuity have a larger amount of savings, including pension savings (Ersner-Hershfield, 2011). Bartels and Urminsky (2011) found that people who are less connected to their future self tend to opt for short-term gains and to demonstrate higher discounting rates. Ersner-Hershfield et al. (2011) managed to prime perceived connectedness to the future self by allowing the subjects to interact with their agedprocessed renderings in virtual reality; after manipulations, subjects were more likely to choose larger later rewards. Ersner-Hershfield et al. (2012) showed that lack of self-continuity leads to unethical behaviour in business: low connected people prefer easy and quick rewards that they can attain with unethical behaviour and they disregard the possible long-term consequences of such behaviour.

Our research contributes to the existing theory by concentrating our attention on the relationship between perceived connectedness to the future self and health behaviour, which was the second objective of our study. In line with previous research, we predicted that perceived connectedness would have a negative effect on temporal discounting rate. In our study, it meant that people with higher connectedness to the future self would demonstrate healthier behaviours in the present. The present study borrowed the measurement of perceived connectedness used in previous research (Bartels \& Urminsky, 2011; Ersner-Hershfield, Garton, et al., 2009). However, for reasons explained in the Measures section, we used an inverted variant of the perceived connectedness to the future self construct called 'perceived change in the future self' (PCFS). Thus, we expected that PCFS would be positively related to unhealthy behaviours and negatively related to healthy behaviours. The hypotheses under investigation were:

H5: PCFS is positively related to unhealthy behaviours. 
H6: PCFS is negatively related to healthy behaviours.

There may be interaction between personality factors (Carver \& Scheier, 2008), thus focusing on main effects exclusively could possibly disguise synergistic or multiplicative relationships between traits (Baron \& Kenny, 1986). Thus, the study tested whether PCFS moderated the relationships between CFC-I and CFC-F, and health behaviours. We assumed that, even if one was generally concerned with the immediate consequences of one's actions, one would try to resist one's immediate desires that are potentially health ruining if one feels connected to one's future self, i.e., score low on PCFS. On the other hand, high perceived change should enhance the positive relationship between CFC-I and unhealthy behaviours, and the negative relationship between CFC-I and healthy behaviours. We also suggested that individuals who score high on CFC-F would not manifest it in their actual health behaviour if they score high on PCFS because they would not associate their future self with their present self. Thus, PCFS was expected to strengthen the effects of CFC-I on health behaviours and weaken the effects of CFC-F. The hypotheses tested were:

H7: PCFS strengthens the positive relationship between CFC-I and unhealthy behaviours. H8: PCFS strengthens the negative relationship between CFC-I and healthy behaviours. H9: PCFS weakens the negative relationship between CFC-F and unhealthy behaviours. H10: PCFS weakens the positive relationship between CFC-F and healthy behaviours Figure 1 presents the conceptual model of the article and summarises the hypotheses. 


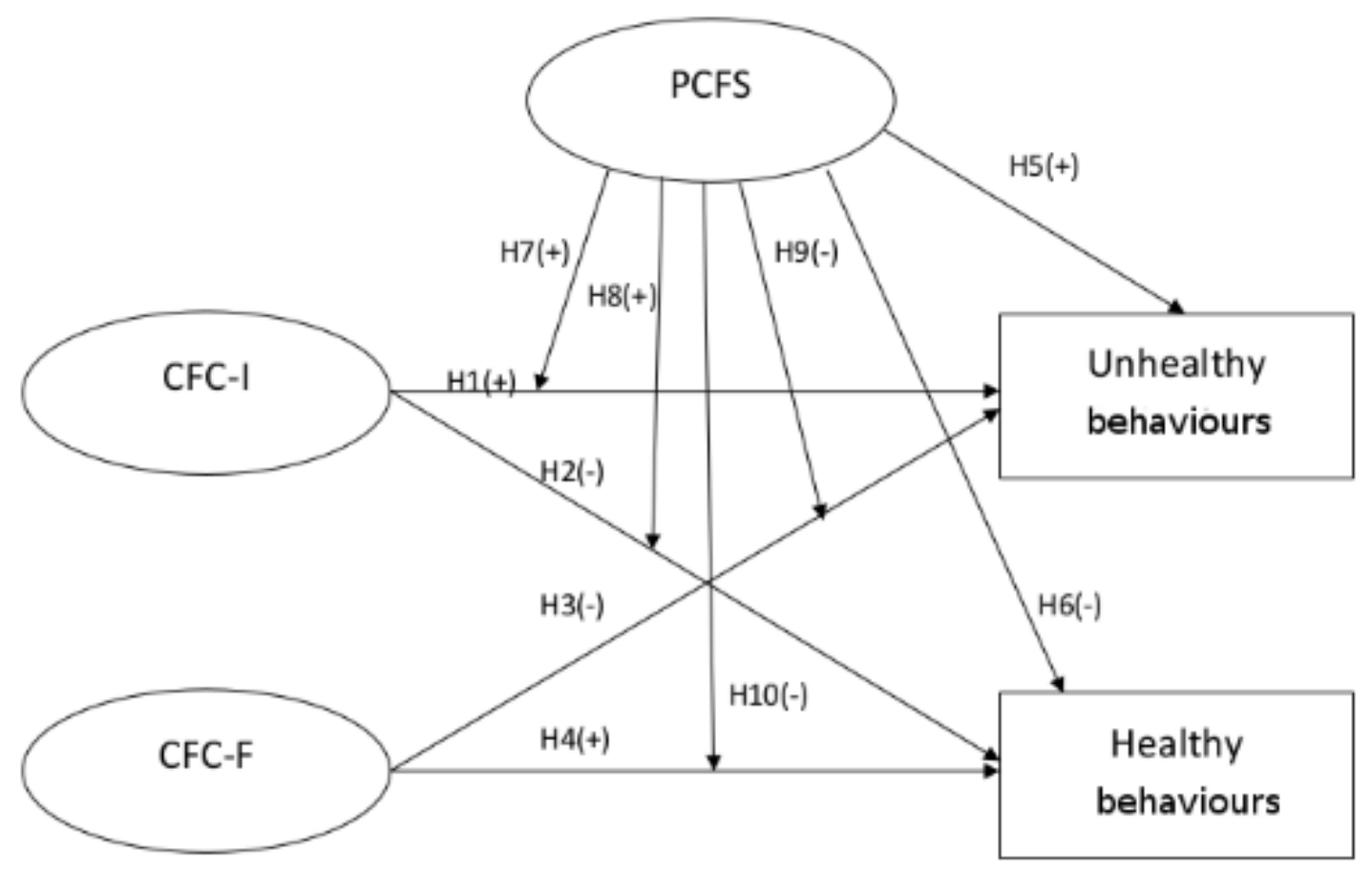

Figure 1. Conceptual model.

\section{Method}

\section{Participants and procedure}

A representative Norwegian population sample was recruited. A total number of 346 participants, 177 women and 169 men, aged between 18 and 65 (mean = 42), answered an online questionnaire. A reputable survey company was hired for data collection. The questionnaire was translated from English into Norwegian.

\section{Measures}

\section{Consideration of immediate and future consequences}

In our work, we operate with the CFC-14 model (Joireman, Shaffer, Balliet, \& Strathman, 2012). Consideration of future consequences was measured with the help of the CFC-14 questionnaire 
(Joireman et al., 2012). All items were rated on a 7-point Likert scale from -3 = 'strongly disagree' to $+3=$ 'strongly agree'.

Perceived connectedness to the future self/perceived change in the future self

Initially, a perceived connectedness measure was borrowed from Ersner-Hershfield, Garton, et al. (2009) and Bartels and Urminsky (2011). However, the pre-test showed that the wording confused the participants: some estimated their perceived degree of change rather than the degree of shared features. Thus, we made changes to our questionnaire by instructing respondents to estimate the degree to which their personality would change in the future, and we inverted the original scale. The participants were given the instruction: 'Think about the important characteristics that make you the person you are now-your personality, temperament, major likes and dislikes, beliefs, values, ambitions, life goals, and ideals'. Then they were asked to estimate how much their personality would change in 1 year/ 10 years/ 20 years and this was measured on an 11-point scale, ranging from ' $0 \%$ change/ absolutely the same person' to ' $100 \%$ change/ completely different people' with an interval of $10 \%$.

In addition, we asked a general question about perceived change. The item was estimated with the help of a 7-point Likert scale from '-3' (completely disagree) to ' +3 ' (completely agree), and was worded as follows: 'To what degree do you agree/disagree with the following statement': 'My personality will change a lot in the future'.

Health behaviour consequences usually occur over many years, thus perceived change in one year would be irrelevant for predicting health choices. Next, a PCFS variable was computed as an average of three items: perceived change in 10 years, perceived change in 20 years, and a general measure of perceived change.

\section{Healthy and unhealthy behaviours}


This study examines two categories of health behaviour: unhealthy (smoking and unhealthy eating) and healthy behaviour (physical activity and healthy eating). Our decision was dictated by the probability that our independent variables could differentially predict these two types of health behaviour (Kalavana, Maes, \& Gucht, 2010). Smoking and unhealthy eating represented unhealthy behaviour in our study, whereas healthy behaviour was expressed by healthy eating and physical activity. All health behaviour measures were self-report behaviour frequency measures with a onemonth timeframe.

Smoking behaviour (SB) was measured with one question: 'How many cigarettes/ pipes have you smoked on average per day during the last month?', and estimated on a 9-point scale where 1 $=0,9=60$ or more per day. The unhealthy eating habits variable (UFood) was a sum of three variables: eating cakes, unhealthy (sweet/salty) snacks, and drinking beverages with high sugar content. The items were measured on a 9-point scale ranging from $1=$ several times per day, $9=$ never. The healthy eating variable (HFood) was computed by the sum of two variables: eating fruit and eating vegetables. The items were measured on a 9-point scale ranging from $1=$ several times per day, $9=$ never. Physical activity (ACT) is a sum of two variables: walking and exercising status. The items were measured on a 6 -point scale ranging from $1=$ every day, $6=$ never. The scores on healthy eating, unhealthy eating, and physical activity were reversed for the analysis so that the higher score would represent higher behaviour frequency.

\section{Data analysis}

First, two confirmatory factor analyses were performed in AMOS.22. We compared a two-factor CFC model versus a one-factor model in order to ensure internal consistency, and the convergent and discriminant validity of the CFC-I and the CFC-F constructs (Anderson \& Gerbing, 1988). Next, we 'imputed' composite CFC-I and CFC-F variables in AMOS. Before proceeding with the 
moderation analysis, we standardised interacting variables (Dawson, 2014). We performed a structural equation analysis of the model, estimating direct and interaction effects simultaneously and plotted them to ease interpretation (Dawson, 2014). The model was controlled for age, gender, and family status (living alone or with others and having or not having children).

\section{Results}

\section{Confirmatory factor analysis}

First, we conducted confirmatory factor analysis for a model with two CFC factors, which demonstrated a bad data fit $($ RMSEA $=.127)$. Three items with low factor loadings were removed from further analyses: CFC-I3: 'My convenience is a big factor in the decisions I make or the actions I take'; CFC-F4: 'I think it is important to take warnings about negative outcomes seriously even if the negative outcome will not occur for many years'; and CFC-I7: 'Since my day-to-day work has specific outcomes, it is more important to me than behaviour that has distant outcomes'. These items have previously resulted in low factor loadings (Joireman et al., 2012; Toepoel, 2010). The new model indicated a satisfactory fit (Hu \& Bentler, 1999): CMIN/df = 2.075, CFI = .948, RMSEA $=.056$. Composite reliability of constructs was higher than .7 (Hair, Anderson, Tatham, \& Black, 1998): CFC-I $=.85$ and CFC-F $=.81$. Table 1 presents correlations between the study variables. 
Table 1. Correlation matrix, standard error, and standard deviation.

\begin{tabular}{llllllll}
\hline & CFC-I & CFC-F & PCFS & SB & UFood & HFood & ACT \\
\hline CFC-I & & & & & & & \\
CFC-F & $-.54^{* * *}$ & & & & & & \\
PCFS & $.14^{* *}$ & $.14^{* *}$ & & & & & \\
SB & $.17^{* * *}$ & -.10 & .04 & & & & \\
UFood & $.29^{* * *}$ & $-.20^{* * *}$ & $.09^{*}$ & .10 & & & \\
HFood & $-.23^{* * *}$ & $.29^{* * *}$ & $-.09 *$ & -.08 & -.05 & & \\
ACT & $-.16^{* * *}$ & $.27^{* * *}$ & $-.10^{*}$ & $-.14^{* *}$ & .00 & $.31^{* * *}$ & \\
Mean & 3.68 & 4.52 & 4.71 & 1.99 & 11.86 & 13.12 & 8.65 \\
SD & .90 & .90 & 1.79 & 1.85 & 3.99 & 3.26 & 2.76
\end{tabular}

Note: $\mathrm{SB}=$ smoking behaviour, $\mathrm{CFC}-\mathrm{I}=$ consideration of immediate consequences, $\mathrm{CFC}-\mathrm{F}=$ consideration of future consequences, PCFS $=$ perceived change HFood $=$ healthy eating, UFood $=$ unhealthy eating, and $\mathrm{ACT}=$ physical activity. ${ }^{*} \mathrm{p}<.1,{ }^{* *} \mathrm{p}<.05,{ }^{* * *} \mathrm{p}<.01$.

To test discriminant validity between CFC-I and CFC-F, we estimated a model with one CFC factor with exactly the same number of items and error term correlations as in the two-factor model (Bagozzi, Yi, \& Phillips, 1991). The model fit was significantly worse: $\mathrm{CMIN} / d f=5.142, \mathrm{CFI}=$ $.786, \mathrm{RMSEA}=.110$. This result suggests that a two-factor CFC model represents the data better. Moreover, there was a moderate correlation between CFC-I and CFC-F, $r=-.54$. In summary, the measures of the proposed constructs achieve high reliability and satisfactory convergent and discriminant validity. 


\section{Structural equation analysis}

Structural equation analysis executed in AMOS demonstrated good data fit (Hu \& Bentler, 1999):

$\mathrm{CMIN} / d f=1.383, \mathrm{CFI}=.996, \mathrm{RMSEA}=.033$. Table 2 summarises the results of the analysis.

Predictive power $\left(\mathrm{R}^{2}\right)$ of the model was the following: $\mathrm{R}^{2} \mathrm{SB}=.04, \mathrm{R}^{2}{ }_{\mathrm{UFood}}=.11, \mathrm{R}^{2}{ }_{\mathrm{HFood}}=.10$, $\mathrm{R}^{2}{ }_{\mathrm{ACT}}=.08$.

Table 2. The results of the path analysis: standardized regression coefficients and significance level.

\begin{tabular}{lllll}
\hline & \multicolumn{2}{l}{ Unhealthy Behaviours } & \multicolumn{2}{l}{ Healthy Behaviours } \\
\hline & SB & UFood & HFood & ACT \\
\hline CFC-I $\rightarrow$ & $.14^{* *}$ & $.21^{* * *}$ & $-.07^{\mathrm{ns}}$ & $.01^{\mathrm{ns}}$ \\
$\mathrm{CFC}-\mathrm{F} \rightarrow$ & $-.02^{\mathrm{ns}}$ & $-.08^{\mathrm{ns}}$ & $.24^{* * *}$ & $.26^{* * *}$ \\
PCFS $\rightarrow$ & $.03^{\mathrm{ns}}$ & $.08^{\mathrm{ns}}$ & $-.11^{* *}$ & $-.13^{* *}$ \\
CFC-IxPCFS $\rightarrow$ & $.08^{\mathrm{ns}}$ & $.14^{*}$ & $-.01^{\mathrm{ns}}$ & $-.10^{\mathrm{ns}}$ \\
CFC-FXPCFS $\rightarrow$ & $.13^{*}$ & $.20^{* * *}$ & $.05^{\mathrm{ns}}$ & $-.12^{*}$
\end{tabular}

Note: PCFS = perceived change in the future self, CFC-I = consideration of immediate consequences, CFC-F = consideration of future consequences, $\mathrm{SB}=$ smoking behaviour, HFood = healthy eating, UFood = unhealthy eating, $\mathrm{ACT}=$ physical activity, $\mathrm{ns}=$ non-significant. ${ }^{*} p<.1$ (90\% confidence level), ${ }^{* *} p<.05$ (95\% confidence level), ${ }^{* * *} p<.01$ (99\% confidence interval).

\section{Direct effects}

There was a significant positive relationship between CFC-I and unhealthy behaviours, i.e., smoking $(\mathrm{p}<.05)$ and unhealthy eating $(\mathrm{p}<.01)$. The paths connecting CFC-I and healthy behaviours, i.e., healthy eating and physical activity, were not significant. Thus, Hypothesis 1, stating that CFC-I would positively relate to unhealthy behaviours was confirmed; whereas 
Hypothesis 2, predicting that CFC-I would be negatively related to healthy behaviours, was not confirmed.

CFC-F had a significant positive relationship with healthy behaviours, i.e., healthy eating ( $\mathrm{p}<$ $.001)$ and physical activity $(\mathrm{p}<.001)$. The relationship between CFC-F and unhealthy behaviours was negative, but non-significant. Thus, Hypothesis 4 that predicted CFC-F would be positively related to healthy behaviours was confirmed; whereas Hypothesis 3 that stated CFC-F would have a negative relationship to unhealthy behaviours, was not confirmed.

The paths between PCFS and unhealthy behaviours, i.e., smoking and unhealthy eating, were positive but not significant. The relationship between PCFS and healthy behaviours, i.e., healthy eating and physical activity, were negative and significant $(\mathrm{p}<.05)$. Thus, Hypothesis 5 was not confirmed, whereas Hypothesis 6 was confirmed.

\section{PCFS as a moderator}

We hypothesised that PCFS would strengthen the positive relationship between CFC-I and unhealthy behaviours (H7) and that it would strengthen the negative relationship between CFC-I and healthy behaviours (H8). PCFS strengthened the positive relationship between CFC-I and unhealthy eating. The moderation effect of PCFS on the link between CFC-I and smoking was pointing in the predicted direction, but was non-significant. The moderation effect of PCFS on the relationship between CFC-I and unhealthy eating was significant at the $90 \%$ confidence interval $(\mathrm{p}=.052)$. The moderation effect of PCFS on the link between CFC-I and healthy behaviours was not significant. Thus, Hypothesis 7 was only partially confirmed, whereas Hypothesis 8 was not confirmed. Figures 2 and 3 present the moderation effect of PCFS on the link between CFC-I and unhealthy and healthy behaviours, respectively. 

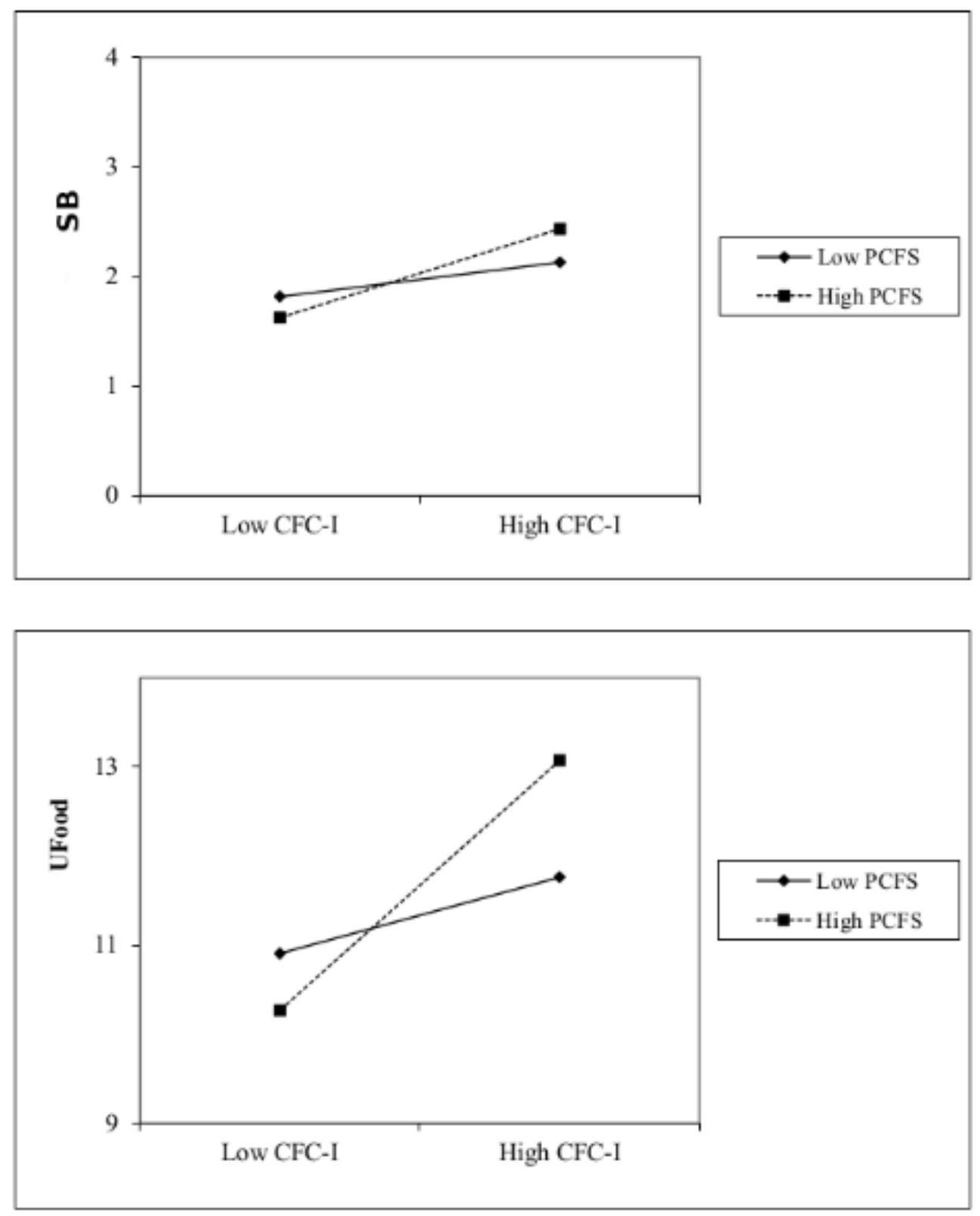

Figure 2. Moderating effect of PCFS on the relationship between CFC-I and unhealthy behaviours. 

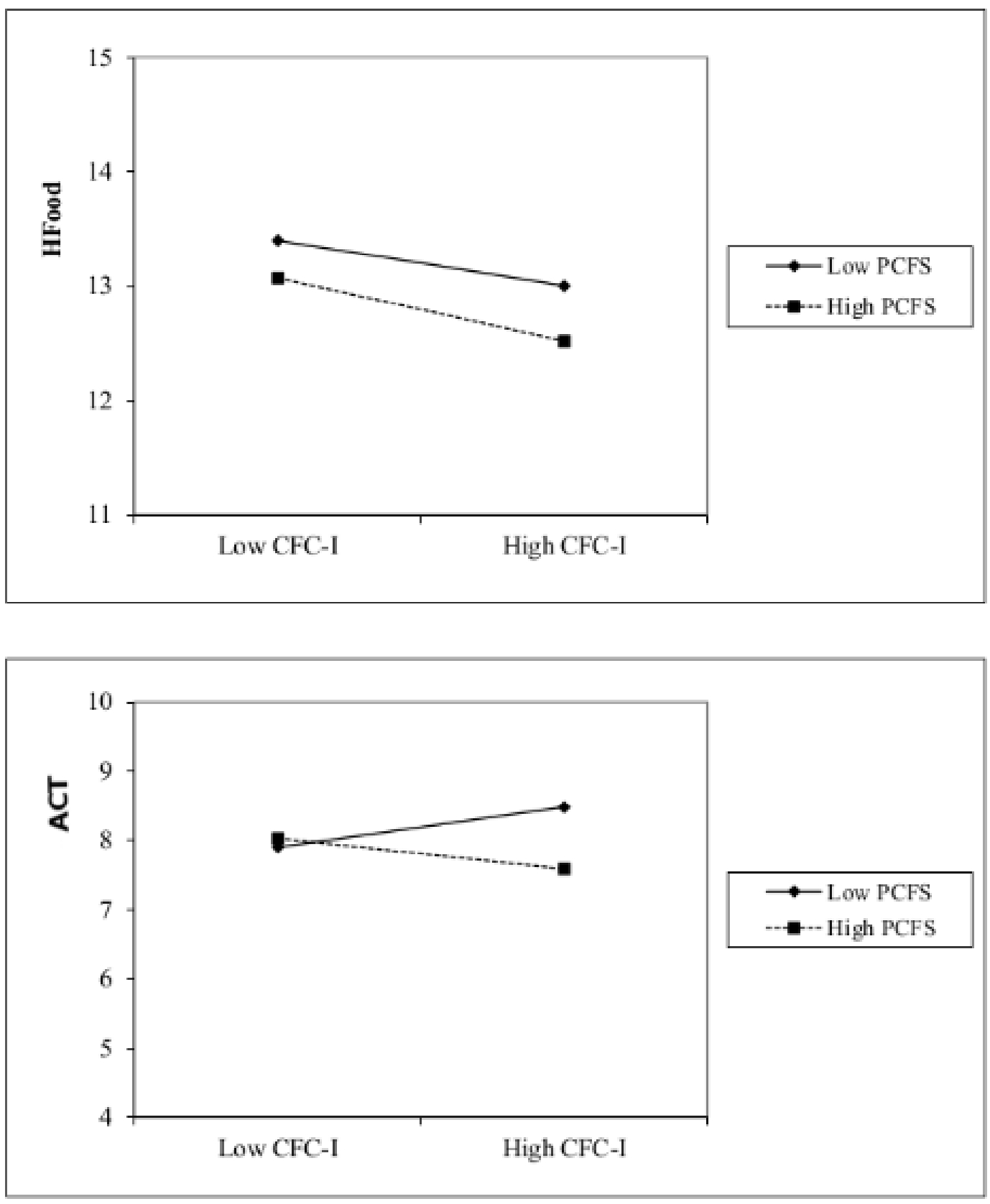

Figure 3. Moderating effect of PCFS on the relationship between CFC-I and healthy behaviours.

We expected that high PCFS levels would weaken the negative effect of CFC-F on unhealthy behaviours (H9), and the positive effect of CFC-F (H10) on healthy behaviours. Hypothesis 9 was confirmed: High levels of PCFS weakened the negative influence of CFC-F on unhealthy eating $(\mathrm{p}<.001)$. The moderating effect of PCFS on the link between CFC-F and smoking was smaller, 
but significant at the $90 \%$ confidence interval $(\mathrm{p}=.069)$. Hypothesis 10 was not confirmed: The moderating effect of PCFS on the link between CFC-F and healthy eating was not significant, and the effect on the link between CFC-F and ACT was negative, as predicted, but barely significant at the $90 \%$ confidence interval $(\mathrm{p}=.099)$. Figures 4 and 5 present the moderation effect of PCFS on the link between CFC-F and unhealthy and healthy behaviours respectively.
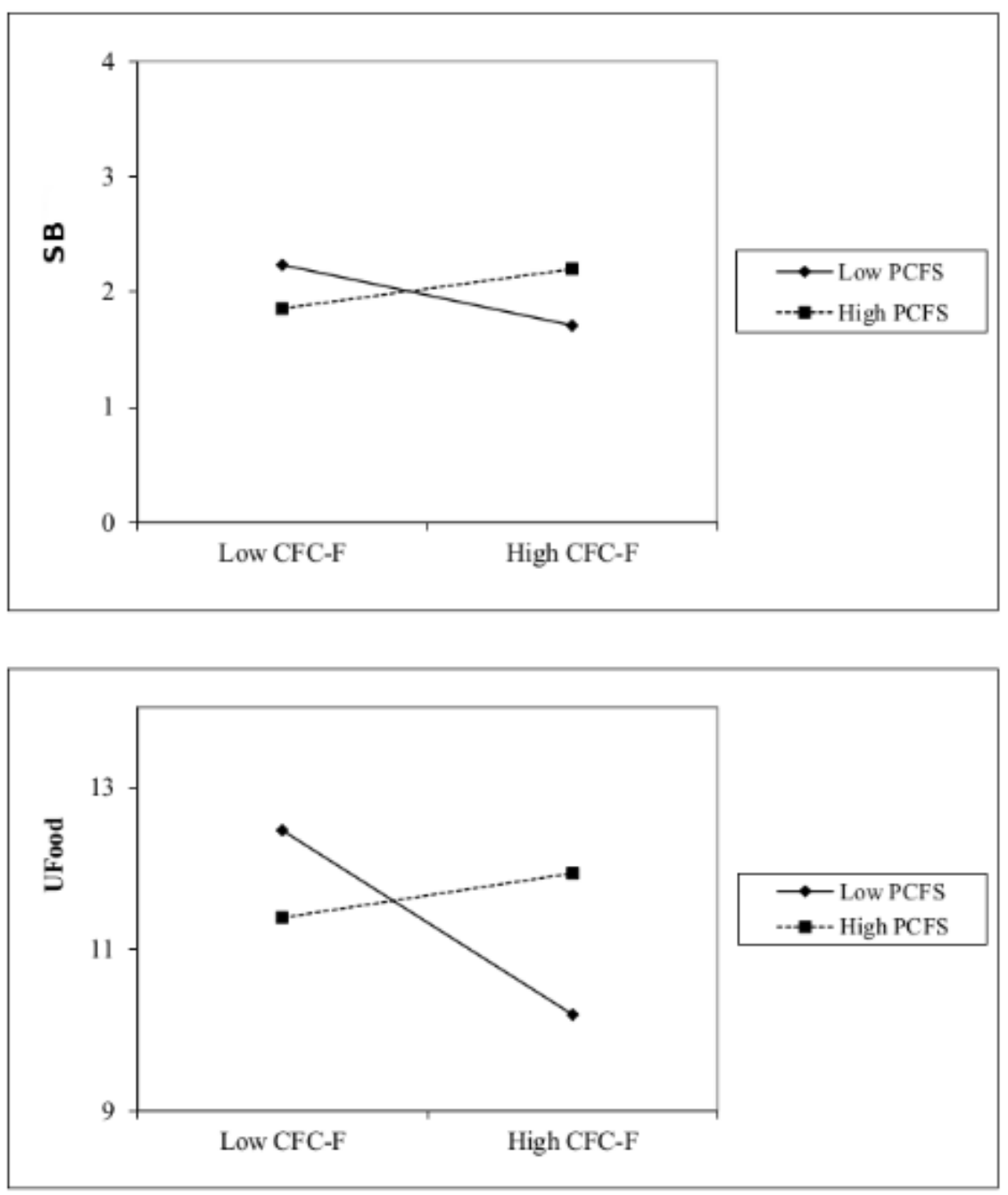

Figure 4. Moderating effect of PCFS on the relationship between CFC-F and unhealthy behaviours. 

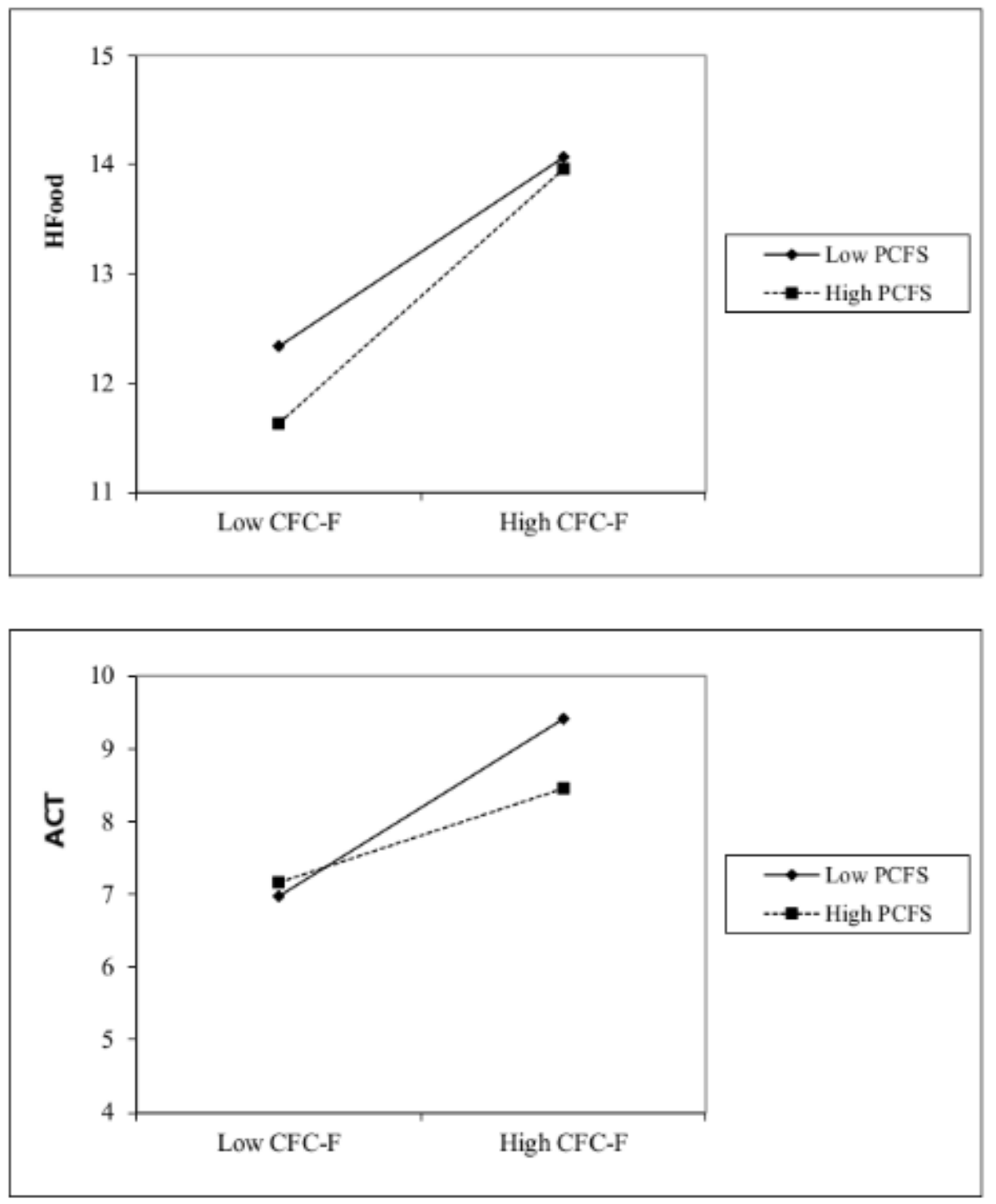

Figure 5. Moderating effect of PCFS on the relationship between CFC-F and healthy behaviours.

\section{Discussion}

The present study contributed to theory development in several ways. First, we tested the relationship between the two factors of CFC and health behaviours with different valence, i.e. healthy and unhealthy behaviours. The results suggest that consideration of immediate and future consequences might differentially predict healthy and unhealthy behaviours. As hypothesised, we 
found that those who were more concerned with the immediate consequences of their actions tended to engage in unhealthy behaviours such as smoking and eating unhealthy food more frequently than those who score lower on CFC-I. Unexpectedly, being concerned with the future outcomes of one's actions did not seem to influence unhealthy behaviours. However, the participants who scored higher on CFC-F were more likely to engage in healthy behaviours such as eating healthy food and exercising, whereas CFC-I did not have an influence on healthy behaviours. These findings suggest that CFC-I might be a stronger predictor of unhealthy behaviours, whereas CFC-F might be a stronger predictor of healthy behaviours. Moreover, these results give support to the earlier findings that consideration of future consequences is a two-factor construct, consisting of CFC-I and CFC-F (Joireman et al., 2008), and gives further ground to the practice of subdividing health behaviours into two categories: healthy and unhealthy behaviours (Kalavana et al., 2010).

From a regulatory focus perspective, our results might suggest that high CFC-I people tended to prefer the immediate benefits provided by unhealthy behaviours but did not try to avoid the costs of healthy behaviours in the present. Whereas high CFC-F individuals tended to engage in healthy behaviours but did not try to avoid smoking or eating unhealthy foods more than low CFCF people. In light of these findings, it would be interesting to consider the relationship between CFC and regulatory focus (Higgins, 1987; Higgins, Roney, Crowe, \& Hymes, 1994). Joireman et al. (2012) studied the relationship between CFCs, regulatory focus, and health intention/ behaviour. The authors studied self-reported healthy behaviours, i.e., healthy eating and exercising. The results of our research suggest that people concerned with immediate consequences would prefer the immediate benefits of unhealthy behaviours, thus adopting promotion behaviour; however, they did not avoid the costs of future-oriented behaviour, thus they 
did not adopt a prevention focus. People concerned with their future would prefer healthy behaviours that gave positive outcomes in the future, thus adopting promotion behaviour, whereas they did not adopt a prevention focus by avoiding unhealthy behaviour. Thus, we can see that future study of the relationship between CFC and regulatory focus in the context of both healthy and unhealthy behaviour is needed.

Second, we were the first to explore the relationship between perceived change in the future self and healthy behaviour and its moderating effect on the relationship between CFCs and health behaviours. The results have shown that PCFS relates healthy and unhealthy behaviours in different ways. PCFS had a direct negative association with healthy behaviours. It could mean that people who believed their personality would greatly change in the future, i.e., those who did not feel psychological connectedness to their future self, were less likely to engage in healthy behaviours. Furthermore, PCFS strengthened the positive relationship of CFC-I and dampened the negative relationship CFC-F with unhealthy behaviours. Though the moderation effect of PCFS on the link between CFC-I and smoking was not significant, we attribute it to one of the limitations of our study.

Previous research has shown that health messages tailored to specific personality traits associated with the desired behaviour tend to be more effective than non-tailored messages (Cheng, 2015; Park, 2012; York, Brannon \& Miller, 2012). Our findings may have practical implications in developing behavioural change therapy and health communication. First, we found that future-oriented people tended to be more engaged in healthy behaviours, but they did not engage less in unhealthy behaviours. Present-oriented people were more engaged in unhealthy behaviours, but were not less engaged in healthy behaviours. These findings might suggest that when promoting healthy behaviours, it could be more beneficial to emphasise their long-term 
benefits. Moreover, the campaigns against unhealthy behaviours might be more effective if they reduced the immediate attractions of the behaviour, whereas emphasising the negative future consequences of an unhealthy behaviour might be less effective. Existing health communication research partially confirms our findings. For instance, de Bruijn and Budding (2016) observed that gain-framed messages were more persuasive than loss-framed messages when combined with long-term consequences. However, further research is needed to investigate the relationship between CFCs, message framing, and health behaviour.

Second, a significant direct negative relation between PCFS and healthy behaviours and a significant moderating effect on the link between time CFCs and unhealthy behaviours might suggest that health communication programs are needed that would contribute to decreasing individuals' perceived future change. To our knowledge, there has been no research studying the effect of PCFS on health communication impact. Future research might consider evaluating the moderating effect of PCFS on the relationship between temporal message framing and health intentions or health behaviour.

A general limitation to our work was a skewed distribution of data on the smoking behaviour scale with little variation: out of 346 respondents, 254 were non-smokers. This could account for non-significant and weak interactions, and rather low explanatory power, $\mathrm{R}^{2} \mathrm{SB}=.04$. Moreover, the low explanatory power of the model and effect sizes could be attributed to the fact that we studied the relationship between general personality factors and specific behaviours. van Beek, Antonides, and Handgraff (2013) have shown that behaviour-specific personality measures have better predictive power. Thus, in future research, behaviour-specific measures of CFC-I and CFCF could be considered. 
Furthermore, the non-experimental study design did not allow us to make conclusions about causality. Thus, we encourage future research on the influence of perceived connectedness to the future self/ perceived change in the future self on health behaviour with the use of experimental design.

In the present study, we used self-report measures of health behaviour that could be susceptible to social desirability and social approval biases (Paul, Rhodes, Kramer, Baer, \& Rumpler, 2005; Prince et al., 2008). Thus, using such measures is unsuitable for some research purposes, such as assessing the exact nutrition intake (Cade, Thompson, Burley, \& Warm, 2002). Nevertheless, behaviour frequency questionnaires remain commonly used for accessing habitual behaviours. Self-report behaviour frequency questionnaires were used by McKay et al. (2013), Henson, M. Carey, K. Carey, and Maisto (2006), Hall and Fong (2003), and Strathman et al. (1994) when establishing links between time perspectives and health behaviour.

\section{References}

Adams, J. (2012). Consideration of immediate and future consequences, smoking status, and body mass index. Health Psychology, 31(2), 260-263.

Adriaanse, M. A., Vinkers, C. D. W., Ridder, D. T. D., Hox, J. J., \& Wit, J. B. F. (2011). Do implementation intentions help to eat a healthy diet? A systematic review and meta-analysis of the empirical evidence. Appetite, 56, 183-193.

Anderson, J. C., \& Gerbing, D. W. (1988). Structural equation modelling in practice: A review and recommended two-step approach. Psychological Bulletin, 103(3), 411-423.

Bagozzi, R. P., Yi, Y., \& Phillips, L. W. (1991). Assessing constructs validity in organizational research. Administrative Science Quarterly, 36, 421-458. 
Barlow, P., Reeves, A., McKee, M., Galea, G., \& Stuckler, D. (2016). Unhealthy diets, obesity and time discounting: a systematic literature review and network analysis. Obesity Reviews, 17(9), 810-819.

Baron, R.M., \& Kenny, D.A. (1986). The moderator-mediator variable distinction in social psychological research: strategic and statistical consideration. Journal of Personality and Social Psychology, 51, 1173-1182.

Bartels, D. M., \& Urminsky, O. (2011). On intertemporal selfishness: The perceived instability of identity underlies impatient consumption. Journal of Consumer Research, 38, 182-198.

Cade, J., Thompson, R., Burley, V., \& Warm, D. (2002). Development, validation and utilization of food-frequency questionnaires - a review. Public Health Nutrition, 5(4), 567 - 587.

Carver, C. S., \& Scheier, M. F. (2008). Perspectives on personality (6 ${ }^{\text {th }}$ ed.). New York: Pearson.

Cheng, B. K. L. (2015). Regulatory fit effects on children's responses to healthy eating promotion: An experiment testing message and celebrity fit. Health Marketing Quarterly, 32(1), 48-64.

Dawson, J. F. (2014). Moderation in management research: What, why, when and how. Journal of Business and Psychology, 29, 1-19.

de Bruijn, G., \& Budding, J. (2016). Temporal consequences, message framing, and consideration of future consequences: Persuasion effects on adult fruit intake intention and resolve. Journal of Health Communication, 21(8), 944-953.

Ersner-Hershfield, H. (2011). Future self-continuity: How conceptions of the future self transform intertemporal choice. Annals of the New York Academy of Sciences, 1235, 30-43.

Ersner-Hershfield, H., Cohen, T. R., \& Thompson, L. (2012). Short horizons and tempting situations: Lack of continuity to our future selves leads to unethical decision making and behaviour. Organizational Behaviour and Human Decision Processes, 117, 298-310. 
Ersner-Hershfield, H., Garton, M. T., Ballard, K., Samanez-Larkin, G. R., \& Knutson, B. (2009). Don't stop thinking about tomorrow: Individual differences in future self-continuity account for saving. Judgment and Decision Making, 4(4), 280-286.

Ersner-Hershfield, H., Goldstein, D. G., Sharpe, W. F., Fox, J., Yeykelis, L., Carstensen, L. L., \& Bailenson, J. N. (2011). Increasing saving behaviour though age-processed renderings of the future self. Journal of Marketing Research, 48, 23-37.

Ersner-Hershfield, H., Wimmer, G. E., \& Knutson, B. (2009). Saving for the future self: Neural measures of future self-continuity predict temporal discounting. Social Cognitive and Affective Neuroscience, 4(1), 85-92.

Frederick, S., Loewenstein, G., \& O’Donoghue, T. (2002). Time discounting and time preference: A critical review. Journal of Economic Literature, 40(2), 351-401.

Hair, J., Anderson, R., Tatham, R., \& Black, W. (1998). Multivariate data analysis (5th ed.). New Jersey: Prentice-Hall, Inc.

Hall, P.A. \& Fong, G.T. (2003). The effects of a brief time perspective intervention for increasing physical activity among young adults. Psychology and Health, 18(6), 685 - 706.

Henson, J.M., Carey, M.P., Carey, K.B., \& Maisto, S.A. (2006). Association among health behaviors and time perspective in young adults: Model testing with boot-strapping replication. Journal of Behavioral Medicine, 29(2), 127 - 137.

Higgins, E. T. (1987). Self-discrepancy: A theory relating self and affect. Psychological Review, 94(3), 319-340.

Higgins, E.T., Roney, C., Crowe, E., \& Hymes, C. (1994). Ideal versus ought predilections for approach and avoidance distinct self-regulatory systems. Journal of Personality, 66(2), 276286. 
Hu, L., \& Bentler, P. (1999). Cutoff criteria of fit indexes in covariance structure analysis: Conventional criteria versus new alternatives. Structural Equation Modeling, 6(1), 1-55.

Joireman, J., Balliet, D., Sprott, D., Spangenberg, E., \& Schultz, J. (2008). Consideration of future consequences, ego-depletion, and self-control: Support for distinguishing between CFCImmediate and CFC-Future sub-scales. Personality and Individual Differences, 45, 15-21.

Joireman, J., Lasane, T., Bennett, J., Richards, D., \& Solaimani, S. (2001). Integrating social value orientation and the consideration of future consequences within the extended norm activation model of proenvironmental behaviour. British Journal of Social Psychology, 40, 133-155.

Joireman, J., Shaffer, M. J., Balliet, D., \& Strathman, A. (2012). Promotion orientation explains why future-oriented people exercise and eat healthy: Evidence from the two-factor consideration of future consequences-14 scale. Personality and Social Psychology Bulletin, $38(10), 1272-1287$.

Kalavana, T.V., Maes, S., \& Gucht V. (2010). Interpersonal and self-regulation determinants of healthy and unhealthy eating behavior in adolescents. Journal of Health Psychology, 15(1), 4452.

Loewenstein, G., \& Prelec, D. (1992). Anomalies in intertemporal choice: Evidence and an interpretation. Quarterly Journal of Economics, 107, 573-597.

Loewenstein, G., \& Thaler, R. H. (1989). Anomalies: Intertemporal choice. Journal of Economic Perspectives, 3(4), 181-193.

McKay, M. T., Percy, A., \& Cole, J. C. (2013). Consideration of future consequences and alcohol use among Northern Irish adolescents. Journal of Substance Use, 18(5), 377-391.

Milfont, T. L., Wilson, J., \& Diniz, P. (2012). Time perspective and environmental engagement: A meta-analysis. International Journal of Psychology, 47(5), 325-334. 
Ouellette, J. A., Hessling, R., Gibbons, F. X., Reis-Bergan, M., \& Gerrard, M. (2005). Using images to increase exercise behavior: Prototypes versus possible selves. Personality and Social Psychology Bulletin, 31(5), 610-620.

Parfit, D. (1971). Personal identity. The Psychological Review, 80(1), 3-27.

Park, S.-Y. (2012). The effects of message framing and risk perceptions for HPV vaccine campaigns: focus on the role of regulatory fit. Health Marketing Quarterly, 29(4), 283.

Paul, D.R., Rhodes, D.G., Kramer, M., Baer, D.J., \& Rumpler, W.V. (2005). Validation of a food frequency questionnaire by direct measurement of habitual ad libitum food intake. American Journal of Epidemiology, 162(8), 806 - 814.

Peters, B. R., Joireman, J., \& Ridgway, R. L. (2005). Individual differences in the Consideration of Future Consequences Scale correlate with sleep habits, sleep quality, and GPA in university students. Psychological Reports, 96, 817-824.

Povey, R., Conner, M., Sparks, P., James, R., \& Shepherd, R. (1998). Interpretations of healthy and unhealthy eating, and implications for dietary change. Health Education Research, 13(2), $171-183$.

Prince, S.A., Adamo, K.B., Hamel, M.E., Hardt, J., Gorber, S.C., \& Tremblay, M. (2008). A comparison of direct versus self-report measures for assessing physical activity in adults: a systematic review. International Journal of Behavioral Nutrition and Physical Activity, 5, 56 80.

Rappange, D. R., Brouwer, W. B. F., Job, N., \& Van Exel, A. (2010). Back to the consideration of Future Consequences Scale: Time to reconsider? Journal of Social Psychology, 149(5), 562584. 
Sirois, F. (2014). Out of sight, out of time? A meta-analytic investigation of procrastination and time perspective. European Journal of Personality, 28(5), 511-520.

Strathman, A., Gleicher, F., Boninger, D. S., \& Edwards, C. S. (1994). The consideration of future consequences: Weighing immediate and distant outcomes of behaviour. Journal of Personality and Social Psychology, 66(4), 742-752.

Toepoel, V. (2010). Is consideration of future consequences a changeable construct? Personality and Individual Differences, 48, 951-956.

van Beek, J., Antonides, G., \& Handgraff, M. J. J. (2013). Eat now, exercise later: The relation between consideration of immediate and future consequences and healthy behavior. Personality and Individual Differences, 54, 785-791.

Verplanken, B., \& Sato, A. (2011). The psychology of impulse buying: An integrative selfregulation approach. Journal of Consumer Policy, 34, 197-210.

Volder, M. L., \& Lens, W. (1982). Academic achievement and future time perspective as a cognitive-motivational concept. Journal of Personality and Social Psychology, 42(3), 566-571.

York, V., Brannon, L., \& Miller, M. (2012). Marketing responsible drinking behavior: Comparing the effectiveness of responsible drinking messages tailored to three possible "personality" conceptualizations. Health Marketing Quarterly, 29(1), 49-65.

Zimbardo, P. G., \& Boyd, J. N. (1999). Putting time in perspective: A valid, reliable individualdifferences metric. Journal of Personality and Social Psychology, 77(6), 1271-1288. 